\title{
Resources to Form Logistics Capabilities: from the Perspective of a Small- or Medium-Sized Subcontractor
}

Inga-Lill Carlsson

The self-archived version of this journal article is available at Linköping University Electronic Press:

http:// urn.kb.se/ resolve?urn=urn:nbn:se:liu:diva-139586

N.B.: When citing this work, cite the original publication.

Carlsson, I., (2008), Resources to Form Logistics Capabilities: from the Perspective of a Small- or Medium-Sized Subcontractor, Supply Chain Forum, 9(2), 6-15.

https:// dx.doi.org/ 10.1080/ 16258312.2008.11517195

Original publication available at:

https:/ / dx.doi.org/ 10.1080/ 16258312.2008.11517195

Copyright: Taylor \& Francis

http:// www.tandfonline.com/ 


\title{
Resources to form logistics capabilities- From the perspective of a small- or medium-sized subcontractor
}

\author{
Inga-Lill Carlsson \\ University of Gävle \& University of Linköping, Sweden \\ inga-lill.carlsson@mekanotjanst.se
}

\begin{abstract}
One way for a small subcontractor to meet increasing global competition is to develop a system supplying ability, which implies more focus on logistical issues and a larger overall responsibility in the supply chain. Certain logistics capabilities have been identified as important to a small- or medium-sized subcontractor in order to cope with the system supplying role. Interviews have been carried out in a multiple case study with the purpose of identifying important resources for a smaller supplier with the ambition of forming logistics capabilities to support system supply. Resources within three different areas have been identified: organizational, competence base, and tools. Conclusions from a comparison among three companies, with different degrees of system supplying services, point out the importance of an organization with clear and distinct responsibilities and authorities. Competencies in logistics and enhanced understanding and use of IT support and communication systems are identified as areas to improve for the smaller companies.
\end{abstract}

\section{INTRODUCTION AND PURPOSE}

The role of small- and medium-sized, locally rooted subcontractors is increasingly important in some regions. Large multinational companies aim to cut costs and with a stroke of the pen may decide to outsource or move their manufacturing to low-cost countries (LCC). In the current climate of toughening competition, one strategy that enables suppliers to meet the strong demands for price reductions and still be able to offer high quality and flexible manufacturing is to take increasingly larger overall responsibility for delivery, that is, to become more of a system supplier.

The role of becoming a system supplier is not homogenous_-it depends on how customers and suppliers interpret the undertaking. It is essential to cope with the increasing complexity in production and to cooperate with customers and subcontractors by suggesting the best production solutions while continuously work on cost reduction and productivity improvement measures. Effective logistical solutions and supply chain management form an essential part of the picture. This also fulfils the desire of larger companies to reduce the number of first tier suppliers. 
Much of the research on logistics has been conducted on large international companies, but comparatively little views conditions from the perspective of a small supplier (Rota, Thierry, \& Bel, 2002). When it comes to resources much has been written about specific areas, such as IT communication, and resources concerning product development have been discussed by many (e.g., Kamath \& Liker, 1994). It is difficult to find a complete picture of what resources are required by a small supplier to form logistics capabilities.

Decisions to form logistics capabilities, for example in management, IT, communication standards, or volume flexibility, imply important strategic aims and directions. The purpose of this multiple case study is to identify important resources for a small- or medium-sized subcontractor with no products of its own, but with the ambition to develop its logistics capabilities to support a system-supplying ability. The research questions are: what resources do these suppliers see as important to acquire, develop, or strengthen and which capabilities are supported by these resources?

Three industrial subcontractors have been studied, chosen for their similar line of business, their different sizes, and different development stages. This paper starts with a literature review, followed by a description of the methodology used. The three companies are briefly presented and the results of the study are described. A discussion relates the findings to the research questions, and the paper is finished with a conclusion and summary.

\section{RESOURCES, CAPABILITIES, AND PERFORMANCE: LITERATURE REVIEW}

A small selection of the literature concerning resources and capabilities and their impact on company performances provides a framework to this study. Chosen strategies influence the development of relations (internal and external) and resources. A resource-based view has been applied in order to find out what the previously mentioned demands could mean to a small supplier in terms of resources and capabilities. Möller, Johansen, and Boer (2003) point out that the resource-based perspective "shifts the focus away from goods and services and towards a knowledge-based perspective which takes insight learning and its effects on the relationship between buyer and supplier into account" (p. 371 ).

Grant (1991) points out the distinction between resources and capabilities, where resources are seen as inputs into the production process (including, for example, capital equipment, skills of individual employees, patents, brand names, finance, and so on) and "the capabilities of a firm are what it can do as a result of teams of resources working together" (p. 120). A firm's resources are identified as the source of its capabilities, which in turn 
results in the main source of the firm's competitive advantage. Capabilities are complex and the interaction between routines requires the cooperation of many different resources. Ray and Ramakrishnan (2006) attempt to elucidate the conceptions by the following definitions:

- Resources are "the tangible and intangible assets of a firm which can be drawn upon by the firm when required to achieve its objective(s)" (p. 4);

- Competence is "a combination of firm-specific resources, each of the resources being under the state of sufficiency, . . . , towards achieving specific organizational objective(s)" (p.15);

- Capability is "a complex combination of appropriate set of competences, . . . , towards achieving specific organizational objective(s)" (p. 16).

Capabilities relate to performance. Sarkar and Mohapatra (2006) advocate a capabilityperformance matrix to establish consistency in supplier performance. They see performance as "the demonstrated ability of a supplier to meet a buyer's short-term requirements in terms of cost, quality, service and other short-term criteria" (p. 152). Capability is defined as "the supplier's potential that can be leveraged to the buyer's advantages in the long term" ( $p$. 152). Long-term relations require suppliers that are both highly capable and good performers.

Sarkar and Mohapatra (2006) also point out another difference: although most performance factors are quantitative and easily measurable, the capability factors are often qualitative and present measurement problems. Despite the fact that these more subjective criteria (e.g., reputation for integrity, communication openness, quality of production facilities, and capacity flexibility) have been found to have a greater impact on the long-term performance, supply managers tend to prefer hard, measurable, objective criteria (Kannan \& Tan, 2003). Developing relationships requires a considerable effort and represents resources that should be protected.

Morash (2001) presents the best practice research concerning supply chain strategies, capabilities, and performance, and differentiates between demand-side and supply-side capabilities. Supply chain strategies focusing on customer closeness (e.g., customized and segmental logistics and agility) are connected to such capabilities as responsiveness, valueadded customer services, innovative solutions, and flexibility while important performance measures relate to customer service and proactive quality. Demand chain strategies, however, focus on operational excellence (e.g., JIT and lean supply chains) and require capabilities such as low logistical costs, availability, coverage, standardization, dependability, and speed. Cost and productivity are the top priorities for performance. 
It is important to note is that there is a minimum of both demand-side and supply-side capabilities that must be developed by a supplier in order to be order qualified, for example, perform on-time delivery and show an absence of customer returns. Morash (2001) then concludes that best practice shows a value congruency among supply chain strategies, capabilities, and performance. Having reached minimum performance levels, suppliers should concentrate on developing those capabilities and performance metrics that support their chosen value focus. In excellent firms Morash finds that demand-side capabilities can be reconfigured, recombined, and resequenced to meet the changing demands of specific customers or market segments and thus form competitive advantages that are easier to attain, more difficult to imitate, and more sustainable than through supply-side capabilities. Morash (2001) also comments on "mass customization" strategies, which he sees as a hybrid of operational excellence and customer closeness strategies, in which the most important capabilities are flexibility and using IT as an enabler.

A long-term customer relationship is desirable, and according to Kamath and Liker (1994), it is the integration of the technology of the supplier that forms its basis. Kamath and Liker (2004) claim that suppliers too must be selective: "smart suppliers scan their major customers constantly to determine which are worthy of being partners" (p. 158). They also claim that successful partnerships depend on the right balance among a supplier's technological capabilities, a customer's willingness to share information, and both companies' strategic requirements. Ellegaard, Johansen, and Drejer (2003) describe some of this from the customer point of view in their "customer attractiveness concept." By focusing on being an attractive business partner the customer influences the supplier to act according to the customer's wishes. This type of relationship often leads to considerable integration and thus promotes interorganizational competencies in order to obtain working synergies-resulting in a certain level of attractiveness on both sides.

Blomgren (1997) discusses the distribution of work within and between companies. He points out the types of requirements to which, for instance, the purchasing department can contribute in contrast to the construction department, and also the influence of the group executive board to different kinds of contributions. Blomgren (1997) sees the difference between external and internal organizational boundaries as more of a difference in degree than a difference in kind. Gadde and Håkansson (2001) claim that "the opportunities for purchasing to act as a link between the engineering functions and suppliers are determined not only by the educational background and the competence of purchasing staff. The organizational design of the buying company is important as well" (p. 11). They also 
conclude that "in a small company there is no need to separate purchasing problems from production or marketing issues" (p. 13). Top management often prefers keeping them together. But Gadde and Håkansson (2001) acknowledge that there are considerable differences between companies, owing to their sizes but also to their extent of vertical integration.

Spekman, Spear, and Karnauff (2002) discuss supply chain competencies and see learning as a key component. They identify three challenges affecting supply chain learning: (1) the dilemma of cooperation versus competition in supply chain partnerships, (2) ensuring that learning happens throughout the supply chain and at different levels for maximum value, and (3) improving learning by a flexible structure--"permeable boundaries permit information to flow into the firm" (p. 53). Blomgren (1997) points out the justified question from a subcontractor's perspective: what do we want to be good at/what are we capable of being good at? Bases are the present capabilities and resources, but development is about what the company strives to achieve in a longer perspective.

In this paper I have chosen to illustrate three types of resources as instruments for strategic management to form desired capabilities and achieve company objectives: organizational, competence-related, and different kinds of tools for efficiency and improvement (see Figure 1). The competence base is seen as central because it is both a result from and the basis of the organization and it influences and is influenced by the tools used. This is particular to small companies that have a limited number of employees and are often "multi-functional," and thus very dependent on personal qualifications and characteristics. A large company often has other opportunities to attract specialists and "customize" desirable competencies. The different types of resources are seen here as interacting and, depending on how they are deployed and developed, shaping different capabilities. This is slightly different from the model by Ray and Ramakrishnan (2006), who use resources as building blocks of competencies and competencies, in turn, as building blocks of capabilities. Relations with customers and suppliers, and internally between different functions, are seen here as both dependent on the company resources and a development factor. 
Figure 1 The analysis model, focusing on resources forming logistics capabilities

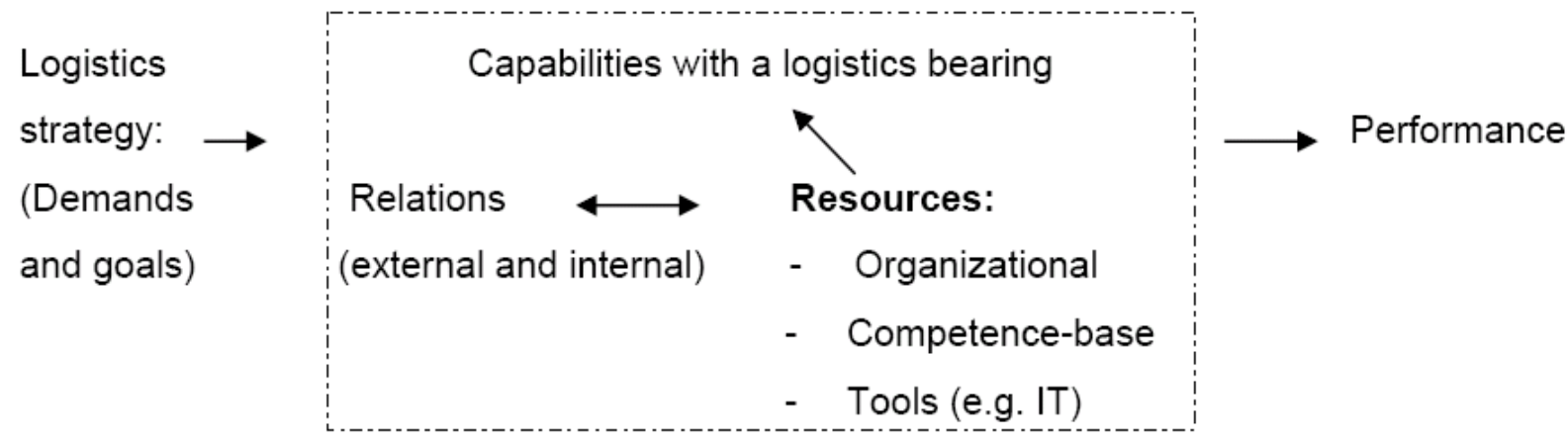

Möller, Johansen, and Boer (2003) sum it up well: "The resource-based perspective concludes that it is the special blend in a corporation's pool of resources which constitutes its competitive advantage. . . . The resource-based perspective also encompasses a strategic bearing, which perceives the corporation as a portfolio of resources rather than products. This implies that the acquisition of skills and know-how becomes an important parameter for the corporation's chances for creating competitive advantages" (pp. 369-370).

\section{METHOD}

This multiple case study is based on previous theory and on the findings of an exploratory survey comparing customer demands on components supply with those on system supply (Carlsson, 2007). System supply here refers to an overall responsibility for the functionality of a product or a system of assembled components, produced in several process steps, and the resulting liability for purchasing material and services. The administered survey indicated a few system competencies-for example, purchasing and logistics, development and project management, liabilities and handling electronic communications-compared to the more generic competencies, for example, delivery precision and short lead-times, quality and environment, price and price-reducing activities, and flexibility.

This multiple case follow-up study aims at finding out what resources a small- or mediumsized supplier values in order to improve system-supplying abilities. I chose to analyze Mekanotjänst because of my double role as a Ph.D. student and business developer at that company. Two other suppliers, Rimaster and Note, were selected for their similar line of business (subcontractors, supplying different manufacturing services) and for their expanding role in different degrees of system supply. Guided interviews (between one and two hours each) were carried out with employees on a managerial level, comprising the 
major part of the management groups in Mekanotjänst and Rimaster, but only one person in Note (though one well up in the company as COO, part-owner and co-founder). My experience from working at Mekanotjänst at a management level and taking part in relevant discussions has given me a good insight and preunderstanding of the subject. As the interviewees represent different functions of the companies the validity of the results is enhanced. The information collected through the interviews and from other sources (web pages, annual reports, internal documents, etc.) is well documented and has been checked with the companies' representatives.

Starting from an understanding of capabilities as defined in earlier research (assessing supplier performance, see e.g. Morash [2001], Sarkar \& Mohapatra [2006]), and confining myself to those with a bearing on logistics, I have chosen to concentrate on eight capabilities: management of the firm, supply chain management, existence of IT standards/communication systems, supplier's proximity, communication openness, cost reduction capability, volume flexibility, and the breadth of product line. The three companies have been compared on the basis of these capabilities. The analysis focuses on resources responding to the previously mentioned system competence-related demands, though omitting the issues concerning development and project management due to the vague connection to logistics.

\section{THE STUDIED COMPANIES}

The three companies are all subcontractors to large industrial customers. They represent groups of companies, with expressed growth strategies and no products of their own. Mekanotjänst and Rimaster are small- or medium-sized companies and represent rather small concerns, with about 250 and 500 employees, respectively, while Note is considerably larger with about 1,200 employees. They meet the criterion of a widened total responsibility and all stress an extensive customer focus while striving to balance different business sectors and market fluctuations. In this study they also represent different stages of development towards system supply.

Mekanotjänst $i$ Järvsö $A B$ (about 120 employees) is one out of four collaborating mechanical subcontractors in a privately owned industrial group. The company describes itself as a complete supplier of mechanics and strives to be included as a production partner from a relatively early stage of the product development process, a goal achieved with some customers. The cooperation within the group enables the company to widen its appeal, an 
important means to developing its role as system supplier. Targeted business sectors are telecom, medical technology, electronics/instruments, and the engineering industry. The circle of customers is rather narrow, consisting of mainly large, internationally active companies with manufacturing units in Sweden, such as Ericsson, ABB, and Maquet.

Rimaster Rimforsa $A B$ (about 160 employees) is also privately owned and part of six integrated companies, including a Polish factory that increases volume production. The company describes itself as a complete outsourcing partner that offers development and production in the fields of electrics, electronics, and mechanics. The positioning between pure cabling and EMS (electronic manufacturing services) is said to make the company an attractive supplier for particular segments. The company has actively been consolidating the customer profile in line with the strategy to be capable to meet the demands of certain customers. Four customer segments are based on specialised skills in customer applications: industrial automation, communication systems, specialised vehicles, and transport vehicles. The customer base is characterised by a few large product-owning international companies, for example, ABB, SAAB, Siemens, and Atlas Copco.

Note $A B$ is an EMS supplier, calling itself a service-producing company and selling the service to assemble customers' products. Note was founded less than ten years ago as an intermediary within the electronic line of business, conveying manufacturing orders from Sweden to Central-European factories. Two Swedish companies, a factory and a sourcing company, were merged in order to obtain production in Poland. Note went public in 2004 (listed on the Stockholm Stock Exchange's O-list) and has a vast customer diversification with several hundred customers. Focus is on four market segments: telecom, industrial, vehicle/maritime, and medical/technology/safety/security, producing electronics from design to after-sale service.

\section{ANALYSIS AND COMPARISON}

My analysis initially compares the two smaller companies to find out what resources they emphasize, and then I made a comparison with the larger company. The two smaller companies have much in common: the focus is still very much on "generic demands" or "hygiene factors"-delivery precision, short lead-times, price, quality, flexibility, and information. To perform well is considered a basic capability. The organizations are customer-focused, reacting rapidly and solving customer problems by taking urgent measures when necessary. Cost, quality, and time are the critical factors to shorten the 
industrialization process. The limited number of customers is in line with the ideas posited by Kamath and Liker (1994) concerning suppliers' selectiveness, and the sales work is directed towards a rather narrow circle of industrial customers. What Ellegaard, Johansen, and Drejer (2003) call the "customer attractiveness concept" is recognized by these suppliers in two ways: they cherish their customer relations as good reference customers and as drivers to develop the business.

More forecast-based production and stipulated fixed lead-times in customer agreements makes efficient planning systems an essential resource. A constant worry is to match customer forecasts with existing capacities. The low accuracy of some customer forecasts disturbs the planning process, resulting in much capital being tied up in stock and increasing risks. The need for more integration-especially towards the customers-is acknowledged. The increased share of purchased material implies larger responsibilities: effective and coherent planning and handling an increased number of suppliers. The supplier-related and logistical issues are seen in both companies as weak spots. Focus is on reducing purchasing prices and costs. Being cost-effective as well as providing coordinated sourcing and logistics within the company groups are important tasks and central purchasing managers have recently been appointed in both companies. The ERP system Monitor is used by both companies and is considered a suitable tool. Mekanotjänst use EDI as a frequent and preferred way of sending order-connected information to customers and suppliers and Rimaster also reports external and internal demands on EDI solutions. A VMI support system is also implemented by both. The processes need to be elucidated and improved, though, as explicitly desired is the process of "early warning" when problems arise.

In some areas the suppliers have had a different focus, for example, about how to handle low-cost sourcing. Mekanotjänst only recently has begun to establish such contacts. Rimaster claims that flexibility is increased and costs are reduced through their manufacturing in the Polish unit (often producing larger volumes and requiring labourintensive production). Small volumes, spare parts, some prototypes, and preserial manufacturing as well as more complex articles are often handled in Sweden. Lean production has been implemented by Rimaster in parts of the production process, and is expected to achieve full effect during 2008. Mekanotjänst see the potential and has started a project to implement lean thinking in its organization. Increasing customer cooperation renders competence levels and competence development within the organization more outspokenly important. This was recognized early by Mekanotjänst, which for some years has been working to discern competence gaps and comparing these demands to the actual situation in order to form training programmes. Rimaster has increased its training focus and 
has started to implement a personnel administration system to handle this. Leadership (e.g., project leaders) and logistics competencies (e.g., production planning), are important issues to both companies.

A series of strategic organizational changes were initiated when the owner of Rimaster stepped down as CEO. The members of the managerial group assert that appointing a new CEO and a production manager made the organization much clearer. A balanced scorecard project some years ago gave the organization a number of key performance ratios, including the importance of clarifying responsibilities and authorities and promoting pro-activity and energy, and was considered to be of great assistance as means of control. An earlier concentration on sales has shifted towards delivery precision, quality performance, efficiency, and productivity of the divisions. Mekanotjänst is still owned and run by the founder, and the organization is perceived as somewhat unclear. Rimaster uses its intranet, accessible to all personnel, to communicate action programmes between different functions, for other information and instructions, forms, and so on, while the intranet of Mekanotjänst lies more or less fallow.

Note stresses geographical location, being "geographically and psychologically close" to the customer. Note has grown through acquisitions in Sweden to be "one hour by car from the customer"; their Excellence Units primarily focus on development, prototype manufacturing, and industrialization, and their industrial plants are units with high production capacity in cost-efficient countries (Poland, the Baltic States, and China), either with their own resources or by collaboration agreements with external plants as "expansion tanks." Complex production-smaller volumes, complex products, and "unstable" products in a development phase or built-in products in larger systems-is retained in Sweden, for the same reason as Rimaster.

A centralized management and service centre (sourcing, human resources, accounting, IT, lean, sales and marketing, production, and corporate communications) manage the units. The goal is now to reach new markets with a larger central organization. The smaller companies also try to coordinate the resources of the company groups, although they have not yet reached as far. Note has fewer suppliers than the other companies but a larger share of personnel at work on global sourcing. The sourcing-central of Note (about 50 employees) enables a comprehensive view of issues such as volumes, products, supplier bargaining position, and sourcing synergies, and the company makes extensive use of IT. A tool developed from the supplier data gives coordinated information directly from the suppliers in a special search system. In some factories the customers may access the ERP systems and 
follow the progress of their articles in the production line. The internet connection facilitates and reduces the manual customer handling, minimizing the administration and increasing the customer value. "Early warnings" are caught through automatized information flows (only at some factories though).

\section{DISCUSSION: WHAT RESOURCES ARE SEEN AS IMPORTANT AND WHICH CAPABILITIES DO THEY SUPPORT?}

As long-term relationships with the customers are highly valued by smaller suppliers, the strategy should be to concentrate on the resources that strengthen and stabilize those kinds of relationships, for example, the competence base, organizational approach and alignment, and tools (see Table 1, where the collected information has been structured accordingly). The concentration on customers within a few branches is evident, stemming from existing production resources and technology competencies considered attractive to customers within chosen segments. The subcontractors benefit by similar customer demands and can still spread the risks and better handle fluctuations in the market. The scarce resources would also compel the smaller subcontractor to prefer some customers to others. A demanding customer means development possibilities but the value for the supplier lies in demands that could be aligned to satisfy several customers and/or rationalize timeconsuming activities. The reputation of a demanding customer is also important-to be a "preferred supplier" is seen as a marketing asset. 
Table 1 Resources connected to capabilities

\begin{tabular}{|c|c|c|c|}
\hline \multirow{2}{*}{ Capabilities } & \multicolumn{3}{|c|}{ Resources } \\
\hline & Organizational & Competence base & Tools \\
\hline $\begin{array}{c}\text { Management } \\
\text { of the firm }\end{array}$ & $\begin{array}{l}\text { Strategic customer } \\
\text { segments. Distinct } \\
\text { responsibilities and goals. } \\
\text { Focus on leadership } \\
\text { (process, project)- } \\
\text { supporting cooperation } \\
\text { between different } \\
\text { organizational teams-no } \\
\text { "functional silos." }\end{array}$ & $\begin{array}{l}\text { Distinct and communicative } \\
\text { leadership. Decisiveness. } \\
\text { Ability to take a "helicopter } \\
\text { view," seeing things from } \\
\text { different angles. A sound } \\
\text { knowledge of the market } \\
\text { and the prerequisites of } \\
\text { production, logistics, and } \\
\text { IT. }\end{array}$ & $\begin{array}{l}\text { Effective meetings within } \\
\text { the executive group. } \\
\text { Business plans, distinct } \\
\text { goals, and KPIs. Relevant } \\
\text { and effective IT systems to } \\
\text { support different functions } \\
\text { and overall analyzing } \\
\text { needs. }\end{array}$ \\
\hline $\begin{array}{l}\text { SCM, including } \\
\text { central sourcing }\end{array}$ & $\begin{array}{l}\text { Central sourcing unit. } \\
\text { Fortified and consolidated } \\
\text { to manage guiding the } \\
\text { subcontractors. }\end{array}$ & $\begin{array}{l}\text { Logistical and purchasing } \\
\text { competencies, contractual } \\
\text { and legal competencies. } \\
\text { Experience from sourcing } \\
\text { in low-cost regions. Fluent } \\
\text { English. }\end{array}$ & $\begin{array}{l}\text { Models to classify articles } \\
\text { and suppliers. Supplier } \\
\text { evaluation and } \\
\text { development tools. Uniform } \\
\text { models for supplier } \\
\text { agreements, logistical } \\
\text { agreements, etc. } \\
\end{array}$ \\
\hline $\begin{array}{c}\text { Existence of } \\
\text { IT standards/ } \\
\text { communication } \\
\text { system }\end{array}$ & $\begin{array}{l}\text { IT policies and structure. } \\
\text { Organizational focus on } \\
\text { deployment and } \\
\text { development of capabilities } \\
\text { such as EDI and web site } \\
\text { for customer/supplier log } \\
\text { in. }\end{array}$ & $\begin{array}{l}\text { Understanding different IT } \\
\text { support systems and } \\
\text { developing their use in the } \\
\text { organization. Educational } \\
\text { as well as technological } \\
\text { skills. }\end{array}$ & $\begin{array}{l}\text { Relevant and effective IT } \\
\text { systems to support } \\
\text { different functions and } \\
\text { overall analyzing needs. }\end{array}$ \\
\hline Supplier's proximity & $\begin{array}{l}\text { Strategy for expansion } \\
\text { (acquisitions or organic } \\
\text { growth-closeness to } \\
\text { customers). }\end{array}$ & $\begin{array}{l}\text { Competence to make well- } \\
\text { founded decisions. } \\
\text { Organizing skills. }\end{array}$ & IT communication systems. \\
\hline $\begin{array}{c}\text { Communication } \\
\text { openness }\end{array}$ & $\begin{array}{l}\text { Constructive about sharing } \\
\text { information with customers } \\
\text { and suppliers. Organized to } \\
\text { support internal and } \\
\text { external cooperation. }\end{array}$ & $\begin{array}{l}\text { Communicative ability. } \\
\text { Understanding the } \\
\text { customers' business. } \\
\text { Different calculation } \\
\text { models. Languages } \\
\text { (especially English). }\end{array}$ & $\begin{array}{l}\text { Formal and informal } \\
\text { meetings. Intranet, web } \\
\text { interfaces, and systems } \\
\text { integration to share more } \\
\text { information with suppliers } \\
\text { and customers. } \\
\end{array}$ \\
\hline $\begin{array}{c}\text { Cost-reduction } \\
\text { capability }\end{array}$ & $\begin{array}{l}\text { Management focus and } \\
\text { strategies for lean } \\
\text { production and effective } \\
\text { sourcing and logistics. }\end{array}$ & $\begin{array}{l}\text { Logistics and purchasing, } \\
\text { production technology and } \\
\text { quality system. Lean } \\
\text { production and } \\
\text { rationalization skills. }\end{array}$ & $\begin{array}{l}\text { Relevant calculation and } \\
\text { costing models. ERP } \\
\text { system. Lean production } \\
\text { system. }\end{array}$ \\
\hline Volume flexibility & $\begin{array}{l}\text { Investment policy } \\
\text { coordinating investments } \\
\text { and market strategy. } \\
\text { Volume manufacturing } \\
\text { units and/or qualified } \\
\text { subcontractors. }\end{array}$ & $\begin{array}{l}\text { Forecasting and capacity } \\
\text { planning, handling and } \\
\text { acting on customer } \\
\text { forecasts. Planning and } \\
\text { production skills. } \\
\text { Experience in volume } \\
\text { manufacturing in LCC. } \\
\end{array}$ & $\begin{array}{l}\text { Volume manufacturing } \\
\text { units and qualified } \\
\text { subcontractors. Decision- } \\
\text { making process regarding } \\
\text { capacity utilization. } \\
\text { Forecasting evaluation. } \\
\text { Process for "early warning." }\end{array}$ \\
\hline $\begin{array}{l}\text { Breadth of product } \\
\text { line/ability of a } \\
\text { supplier to supply a } \\
\text { number of items }\end{array}$ & $\begin{array}{l}\text { Organized to cooperate for } \\
\text { system deliveries within the } \\
\text { company group and with } \\
\text { external partners. }\end{array}$ & $\begin{array}{l}\text { Logistics and purchasing. } \\
\text { Planning (production } \\
\text { logistics). Production } \\
\text { technology and quality } \\
\text { system. }\end{array}$ & $\begin{array}{l}\text { Relevant calculation and } \\
\text { costing models. Quality } \\
\text { system. }\end{array}$ \\
\hline
\end{tabular}

As the suppliers are often measured and evaluated on the basis of performance instruments such as quality ratings or delivery precision, naturally these areas are seen as very important, as "order-qualifiers." The hard, measurable, objective criteria are obviously very important (Kannan \& Tan, 2003). In the long run, being able to cope with these factors creates other factors that are instrumental in achieving competitiveness. All three suppliers 
in this study claim to focus on customer closeness and should, according to the findings of Morash (2001), concentrate on supply chain strategies, prioritizing resources that add to responsiveness, value-added customer services, innovative solutions, and flexibility. It is however obvious that the smaller companies feel compelled to fight a war on two fronts here-partly because they are not altogether comfortable with the minimum performance levels and partly because the downward pressure on prices forces them to focus more on cost and productivity. Their limited resources call for collaboration with competent suppliers and customers. They need employees with a thirst for knowledge and the ability to manage the acquired knowledge within the organization and use it as a stepping stone to add value to the customers.

\subsection{Organizational}

An expected effect of a customer's outsourcing of its production processes is the exchange and broadening of knowledge between customer and supplier, which in turn should promote renewal and innovation of products, production, and processes (Quinn, 1999). This requires that knowledge exchange and cooperation is supported throughout the organization, minimizing the "functional silos" and trying to take advantage of different resources to build "organizational routines" (Grant, 1991, p. 122). All three suppliers claim they do this, though the extent varies. The most frequently mentioned actions are cooperation between sales and construction or production engineering. Collaboration within the company groups is an important means of widening the customer offer.

Both Rimaster and Mekanotjänst especially stress the importance of competent and capable leaders on different levels-strategically as well as operationally. This is well in accordance with the importance Teece, Pisano, and Shuen (1997) stressed on how a company coordinates, combines, and develops its different assets. Distinct responsibilities and goals are pointed out as important. Rimaster especially has experienced very positive development from clarifying these in the organization while Mekanotjänst is struggling to improve this.

Demands on purchasing and logistics are considerably higher on system suppliers and more dependent on broad competencies and a wide contact net in order to take on larger complex assignments. A centrally managed sourcing unit to increase and develop the supplier base is considered essential. Rimaster and Mekanotjänst both recently appointed a central purchasing and logistics manager to coordinate the business, and Note maintains a central sourcing unit. 
A system supplier must be aggressive in establishing cost and prices affecting the end customer. Productivity is important, but so is quality, delivery precision, flexibility, and so on. Global sourcing from low-cost regions is required. Establishing manufacturing units in China to serve the customer there is desirable but risky. Rimaster already has a Polish production unit and considers this experience very valuable for future expansion. Lean production is an effective means of cost reduction to Note. Rimaster has chosen to implement lean production in parts of their manufacturing and plans to expand this, and Mekanotjänst is shortly initiating a lean production project. IT investments are recognized as a means of making communication more effective and to relieve the pressure on the administration. However, it is important that the different functions learn to adopt new IT tools wisely and revise their routines and processes accordingly.

\subsection{Competence base}

Customers wants a system supplier to understand the complete product, or at least see its own module system as a whole, and be able to suggest improvements in order to optimize the final results in terms of function, cost, lead-time, and so on. The products are complex and quality as well as production are emphasized. A system supplier should be able to analyze technical problems and report conclusions. The ability to troubleshoot and look up new subcontractors to solve questions within new problem areas is also stressed.

All three suppliers claim that their ability to maintain close relations with their customers and their ability to react quickly to customer requests are very important to their business performance. Some of the capabilities that the managers of Rimaster and Mekanotjänst emphasize (e.g., a "fleet-footed organization," rapid solutions and flexibility) are of a kind that could be considered cultural-perhaps an effect of having developed from a small firm in the hands of one owner for a long period of time. Barney (1996) and Coff (1999) both point out the importance of identifying competencies or success factors affecting the performance of a company, especially knowledge-based assets that are hard to imitate because of firm specificity, social complexity, and causal ambiguity. Note has managed to clarify the competencies of the company more clearly, in "productified" service offers.

Logistical competencies are pointed out as important, as well as purchasing competence and production competence. Supply chain management is an underdeveloped area in the two smaller suppliers, Rimaster and Mekanotjänst. Historically, purchasing was seen as a simple task ("calling off goods") and the purchaser's role was rather "low-status." This has 
changed considerably during the last five years, but there is still a lot of work to do to alter that attitude. During 2007 both suppliers strengthened their organizations with an overall purchasing manager, but the first focus for both suppliers is now on cost reduction. Supply chain management is not given all that much priority. The alignment of the fundamental management components that according to Lambert and Cooper (2000) is necessary to support the supply chain objectives and operations is not yet at hand. As the purchasing manager of Rimaster explain it: "the organization must mature in these matters." Note, however, has been working with these issues from the start and has achieved much more. All suppliers mention the problematic unreliable forecasts from the customers. The importance of understanding the different IT support systems and developing their use is vital to coping with the increasing demands of shorter time spans and reduced costs.

Sourcing in low-cost countries is thought to demand high volumes and long lead-times. An ambition to keep as much production as possible in or nearby Sweden is also noted. The striving is for increased complexity as well as productivity, in competition with "best cost countries". Proximity to the customer is seen as more important, facilitating an increased service level (small quantities, frequent deliveries, etc.). The need for profound knowledge in foreign languages, at the very least English, comes with global customers and global sourcing. This could be a problem for a smaller company that has developed in a local region and also made a good deal of internal recruiting, especially when it comes to the more formal English required in contractual discussions.

The increased overall responsibility as a system supplier is recognized by the suppliers. Delivering a larger part of a finished product requires a larger responsibility and a broader range of liabilities. The need for both a managerial comprehensive view and skilled operators is clear.

\subsection{Tools}

In order to handle a complex composition of demands, the routines requiring most personnel activities must be supported by both working models and relevant and competent IT systems. A highly automatized administration is absolutely necessary to keep the costs down and still be able to render support to the customers and the organization itself. The managers of the suppliers emphasized the importance of reducing the share of customer unique handling. Using more of the existing system support in a better way is considered desirable. 
Both Rimaster and Mekanotjänst need to adapt models to classify articles and suppliers in order to allow the purchasing work to be more effective. Models to calculate and follow up total cost in a consistent manner and models to assess forecasts according to uniform standards within the company are other examples mentioned by Mekanotjänst. Developing uniform models, such as supplier agreements and logistical agreements, is also seen as important.

In order to mechanize some routines, different IT support systems are important, for example, in ERP, electronic communication systems, and document handling. Different technical systems are necessary for the product engineers who work with drawings as well as with three-dimensional models and prerequisites for complex production machines. Utilizing IT to share more information with suppliers and customers is well developed by Note, but much less focused by Rimaster. Mekanotjänst is advancing its capabilities in EDI concerning order information but still sees the need to expand the electronic communication. Examples of information discussed by Mekanotjänst were forecasts, supplier information (early warnings), capacity information, drawings, offerings, and so on.

\section{CONCLUSION AND SUMMARY}

The important concepts regarding resources for small- or medium-sized suppliers are a clear organization, with a distinct and communicative leadership, and relevant and effective IT systems to support communication solutions. Logistical and purchasing competencies are mentioned as the most important for a small subcontractor to develop in order to cope with the demands of system supply. Experience from low-cost sourcing and from handling customer forecasts are also mentioned as important competencies to improve performances and reduce costs and risks of the companies. These resources support a number of important capabilities with an emphasis on logistics: management, SCM, existence of IT standards, and cost-reduction capabilities. Production capacity and support by qualified subcontractors are necessary resources to handle another demanding capability: volume flexibility.

Having a clear organization and a distinct and communicative leadership are pointed out by all three companies as significant resources. Putting together a management that has foresight, a sound knowledge of the market and the competitive situation, as well as the prerequisites of production, logistics, IT, and so on in a small company could be a challenge, 
however. Finding people with the right competencies and being able to attract and employ them is one part; affording them is another challenge. The operative work of the day is often prioritized before strategic management. Therefore, it is especially important to elaborate strategic business plans, supported by and communicated through distinct goals, and KPIs. An advantage of the small, privately owned companies is the often short decision-making processes.

All three companies claim to have a very clear customer focus, stressing the importance of personal relations. They seem to aim at a mixed focus of productivity and customer closeness. Although the strategy is on customer focus, the cost reduction demands from customers and the profitability demands within each company occupy much of the resources, especially in the smaller companies with more limited assets. Note has developed more distinct profiles regarding customer closeness (near sourcing) as well as cost savings: lean manufacturing, production units in low-cost countries, centralized group-wide sourcing, and so on. Rimaster is well on the way with the same measures for cost reduction, but Mekanotjänst still has not quite decided about their direction. Both Rimaster and Mekanotjänst find the volume flexibility demanding, but they also stress their ability to react rapidly and to solve customer problems by taking urgent measures when necessary. The reliability of the forecasts from some customers is often rather poor, which causes problems in capacity planning and advance planning towards the suppliers. Realizing Morash's (2001) views about mass customization necessitates more resources that enhance the flexibility and IT that provides planning and communication tools.

The cost aspect of global sourcing occupies all companies. This is a demanding task for a minor company, requiring a lot from the organization, but considered necessary to develop. To establish manufacturing in its own units in China is by both the smaller companies regarded as advantageous, though risky. Rimaster considers the experience from the Polish unit to be an important advantage. Note has established its own production units in the Baltic states, Poland, and China. To coordinate the sourcing within the company group is considered important. Logistical issues also have an increased focus. From a manufacturing perspective, the smaller companies previously looked at purchasing as merely supporting the process of "supply on call." This has changed and both companies have appointed qualified central purchasing managers. Note, however, has from the start purchased production services as efficiently as possible for their customers, which has also led to acquisitions of production units. 
The demand for a more comprehensive view must be reflected in the organizationspecifically recognizing that in Mekanotjänst, for example, the technology competence is more outspoken within the marketing personnel than with the responsible purchasers. The marketing personnel also have the most contact with the customers and thus get first-hand information about material requirements, cost limits, and so on. The possibility of making use of subcontractors' materials knowledge is thereby diminished. Most of the respondents from the three companies are of the opinion that the manufacturing processes are more or less similar to their competitors. Effective production is required by all! And as the CEO of Mekanotjänst put it: logistics will "sort out the wheat from the chaff."

\section{References}

Barney, J. (1996). The resource-based theory of the firm. Organization Science, 7(5), 477501.

Blomgren, H. (1997). Arbetsfördelningen i produktionskedjan mellan underleverantörer och köpande företag. Stockholm: Nerenius \& Santerus Förlag AB.

Carlsson, I.-L. (2007). Towards system capability: Identifying logistics and manufacturing demands for small suppliers. Paper presented at the 2007 European Operations Management Association Conference, Ankara, June.

Coff, R. (1999). When competitive advantage doesn't lead to performance: The resourcebased view and stakeholder bargaining power. Organization Science, 10(2), 119-133.

Ellegaard, C., Johansen, J., \& Drejer, A. (2003). Managing industrial buyer-supplier relations-The case for attractiveness. Integrated Manufacturing Systems, 14(4), 345-356.

Gadde, L.-E., \& Håkansson, H. (2001). Supply network strategies. Chichester: John Wiley \& Sons.

Grant, R. (1991). The resource-based theory of competitive advantage: Implications for strategy formulation. California Management Review, 33(3), 114-135.

Kamath, R., \& Liker, J. (1994). A second look at Japanese product development. Harvard Business Review, 72(6), 154-170.

Kannan, V., \& Tan, K.-C. (2003). Attitudes of U.S. and European managers to supplier selection and assessment and implications for business performance. Benchmarking: An International Journal, 10(5), 472-489.

Lambert, D., \& Cooper, M. (2000). Issues in supply chain management. Industrial Marketing Management, 29(1), 65-83. 
Möller, M., Johansen, J., \& Boer, H. (2003). Managing buyer-supplier relationships and interorganisational competence development. Integrated Manufacturing Systems, 14(4), 369379.

Morash, E. (2001). Supply chain strategies, capabilities, and performance. Transportation Journal, 41(1), 37-54.

Quinn, J. (1999). Strategic outsourcing: Leveraging knowledge capabilities. Sloan Management Review, 40(4), 9-21.

Ray, S., \& Ramakrishnan, K. (2006). Resources, competences and capabilities conundrum: A back-to-basics call. Decision, 33(2), 1-24.

Rota, K., Thierry, C., \& Bel, G. (2002). Supply chain management: A supplier perspective. Production Planning \& Control, 13(4), 370-380.

Sarkar, A., \& Mohapatra, P. (2006). Evaluation of supplier capability and performance: A method for supply base reduction. Journal of Purchasing \& Supply Management, 12(3), 148163.

Spekman, R., Spear, J., \& Kamauff, J. (2002). Supply chain competency: Learning as a key component. Supply Chain Management: An International Journal, 7(1), 41-55.

Teece, D., Pisano, G., \& Shuen, A. (1997). Dynamic capabilities and strategic management. Strategic Management Journal, 18(7), 509-533. 